\title{
Bir Üniversite Hastanesinde Görev Yapan Hemşirelerin Farmakovijilans Hakkında Bilgi, Tutum ve Uygulamalarının Değerlendirmesi*
}

\author{
Evaluation of Knowledge, Attitude and Practices of Nurses Working in a University Hospital about \\ Pharmacovigilance
}

Rukiye Nalan Tiftiki, İbrahim Dumani, İsmail Ün ${ }^{\text {iii }}$

'Dr. Öğr. Üyesi. Mersin Üniversitesi Tıp Fakültesi, Tıbbi Farmakoloji Anabilim Dalı, https://orcid.org/0000-0001-7277-3369

iiMSc. Mersin Üniversitesi Tıp Fakültesi Hastanesi, https://orcid.org/0000-0002-3961-5702

iiiProf. Dr., Mersin Üniversitesi Tıp Fakültesi, Tıbbi Farmakoloji Anabilim Dalı, https://orcid.org/0000-0001-6442-4185

öz

\begin{abstract}
Amaç: Advers ilaç reaksiyonlarının tespit edilmesi ve izlenmesi ilaç güvenliği açısından zorunlu olmasına rağmen, ülkemizde advers ilaç reaksiyonu bildirimi yetersizdir. Öte yandan hemşirelerde farmakovijilansın önemi hakkında farkındalık yaratmak advers ilaç reaksiyonu bildirimi için önem arz etmektedir. Bu çalışmanın temel amacı bir üniversite hastanesinde çalışan hemşirelerin farmakovijilans konusundaki bilgi, tutum ve uygulamalarını değerlendirmektir.
\end{abstract}

Yöntem: Kesitsel ve tanımlayıcı tipte yapılan bu çalışmada, Mersin Üniversitesi Hastanesinde çalışan hemşirelerin farmakovijilans konusunda bilgi, tutum ve uygulamalarını değerlendirmek için 25 soruluk anket uygulanmıştır.

Bulgular: Hemşirelerin \%83,9'u farmakovijilansı doğru tanımlamış ve \%40,7'si hastanede bir farmakovijilans irtibat noktasının olduğunu bilmiştir. Hemşirelerin \%81,7'si advers ilaç reaksiyonu bildiriminin profesyonel bir yükümlülük olduğunun farkındadır. Hemşirelerin \%48,8'i yaşanan bir advers ilaç reaksiyonu gördüğünü bildirmekle birlikte sadece \%0,2'si advers ilaç reaksiyonu bildirimi yaptığını ifade etmiştir. Yaşanan bir advers ilaç reaksiyonunu tanımlamada hemşirelerin $\% 75,1^{\prime} i$ karar vermenin zor olduğunu bildirmiş ve advers ilaç reaksiyonunu bildirmek için hemşirelerin \%36,6'sı yeterli zamanlarının olmadığını sebep olarak göstermişlerdir.

Sonuç: Bu çalışmada araştırmaya katılan hemşirelerin farmakovijilans ile ilgili bilgi, tutum ve uygulamalarında eksiklikleri olduğu görülmüştür. Hemşireler arasında advers ilaç reaksiyonu bildirimi oranı çok düşüktür. Hastanelerde hemşireler için farmakovijilans ile ilgili eğitimler düzenlenmeli ve hemşirelerin bu süreçte yer almaları sağlanmalıdır. Bu şekilde advers ilaç reaksiyonlarının bidiriminde hemşirelerin gerekli katkıyı sunması sağlanabilir.

Anahtar Kelimeler: Advers ilaç reaksiyonu, farmakovijilans, hemşire

\section{ABSTRACT}

Aim: Although detection and monitoring of adverse drug reactions is mandatory for drug safety, the reporting of adverse drug reactions are insufficient in our country. On the other hand, raising awareness of the importance of pharmacovigilance among nurses is important for reporting adverse drug reactions. The main purpose of this study is to evaluate the knowledge, attitudes and practices about pharmacovigilance of nurses working in a university hospital.

Methods: In this cross-sectional and descriptive study, a 25-question questionnaire was applied to evaluate their knowledge, attitudes and practices on pharmacovigilance to nurses working in Mersin University Hospital.

Results: $83.9 \%$ of the nurses defined the pharmacovigilance correctly and $40.7 \%$ knew that there was a pharmacovigilance contact point in the hospital. $81.7 \%$ of nurses are aware that reporting adverse drug reactions is a professional obligation. While $48.8 \%$ of the nurses reported that they had experienced an adverse drug reaction but only $0.2 \%$ of them had reported an adverse drug reaction. $75.1 \%$ of the nurses reported that it was difficult to decide on an adverse drug reaction and $36.6 \%$ of the nurses showed that there was not enough time to report an adverse drug reaction.

Conclusions: In this study, it was observed that nurses participating in the study had insufficiency in knowledge, attitude and practices related to pharmacovigilance. The rate of adverse drug reaction reporting among nurses is very low. Pharmacovigilance training should be organized for nurses in hospitals and nurses should be involved in this process. In this way, it could be ensured that nurses make the necessary contribution to the reporting of adverse drug reactions.

Keywords: Adverse drug reaction, pharmacovigilance, nurse

*Lokman Hekim Dergisi, 2019; 9 (3): 285-293

DOI: $10.31020 /$ mutftd.581540

e-ISSN: $1309-8004$

Geliş Tarihi - Received: 24 Haziran 2019; Kabul Tarihi - Accepted: 08 Temmuz 2019

iletişim - Correspondence Author: Rukiye Nalan Tiftik <nalantiftik@yahoo.com> 


\section{Giriş}

Farmakovijilans, Dünya Sağlık Örgütü tarafından "ilaçların ya da ilaçla ilgili diğer olası sorunların olumsuz etkilerinin tespiti, değerlendirilmesi, anlaşılması ve önlenmesi ile ilgili bilim ve faaliyetler" olarak tanımlanmıştır., ${ }^{1,2}$ Farmakovijilans ilacın güvenli ve rasyonel kullanımı açısından önemlidir. Advers ilaç Reaksiyonu (AIR) bir ilacın normal dozlarda kullanıldığında görülen istenmeyen reaksiyonlarıdır ve hastalarda önemli mortalite ve morbiditeye neden olur. ${ }^{2-4} \mathrm{Bu}$ nedenle $\mathrm{AIR}^{\prime}$ 'n güvenliği açısından zorunlu olmasına rağmen, yapılan çalışmalarda AíR bildiriminin yetersiz olduğu gösterilmiştir. ${ }^{5,6}$ Gün geçtikçe ilaç ürünlerinin çeşitliliğinde ve sayısında meydana gelen artış, sadece ülkemizde değil aynı zamanda tüm dünyada toplum sağılığı açısından en önemli problemler arasında yer alan ilaç güvenliğinin takibini önemli kılmaktadır. Bununla birlikte ilaçlara bağlı oluşan advers etkiler nedeniyle artan mortalite ve morbidite oranları, hastanede yatış süresinin uzaması, iş gücü kaybı ve bunun gibi durumların neden olduğu ekonomik sonuçlar toplumun genelini etkileyen ve çözülmesi gereken bir sorun olarak karşımıza çıkmaktadır. ${ }^{8}$

1961 yılında yaşanan ve dünya tıp tarihindeki en önemli olaylardan biri olarak kabul edilen Thalidomide Faciası'nı takiben başta $A B D$ ve İngiltere olmak üzere birçok ülkede ilaç güvenliliğinin tespiti için ulusal verilerin toplanmasına yönelik adımlar atılmaya başlanmıştır. 1973 yılında Fransa'da ilk ulusal (özerk) farmakovijilans merkezi kurulmuştur. ${ }^{8}$ Ülkemizde ise farmakovijilans ile ilgili düzenlemeler ilk olarak 2005 yılında yayınlanmış ve doktor, eczacı, hemşire, ebe, diş hekimi dâhil sağlık profesyonellerinin bildirim için yetkili oldukları bu düzenlenme ile yasal olarak tanımlanmışır. ${ }^{7}$ Tedavi sonucunun iyileştirilmesi için doktorlar, hemşireler ve eczacılar gibi sağılı hizmeti sağlayıcılarının ortak sorumlulukları vardır. ${ }^{9}$

Türkiye'de yapılan birkaç çalışma sağlık profesyonellerinin farmakovijilans hakkındaki bilgi düzeyi ile AíR rapor etme bilincinin düşük olduğunu göstermiştir. ${ }^{5,6}$ Sağlık profesyonellerinin AíR rapor etme konusunda duyarlı olmaları ve motive edilmeleri gerekmektedir. Sağlık profesyonelleri arasında hemşirelerin hastaya bakım verme, tedavi edici, eğitici, araştırıcı, yönetici, karar verici, özerk ve sorumluluk sahibi olma vb. birçok mesleki rolleri vardır. ${ }^{10}$ Günümüzde hastalarla en çok temas halinde olan hemşireler, ilaç uygulamalarında ilaçların güvenlik prensiplerini esas alarak tedavi edici mesleki rollerini uygulamalıdırlar. İlaç uygulamadan sonra ilaçların etkilerini ve yan etkilerini gözlemlemeli ve buna göre gerekli tedbirlerin alınmasını sağlamalıdırlar. ${ }^{10,11}$ İlanda'da yapılan bir pilot çalışma, hemşirelerin şüpheli AíR'larını kendiliğinden raporlanması yoluyla ilaç güvenliğine önemli ölçüde katkıda bulunabileceğini göstermiştir. İtalya'da yapılan bir başka çalışmada da, hemşirelerin beklenmedik advers olaylar için iyi gözlemsel becerilere sahip olduğunu, ancak AiR'larını tanımlamada zayıf becerilere sahip olduğunu göstermiştir. Bir başka çalışmada ise hemşirelerin AiR'larının tespitine dâhil edilmesinin, süreci nicel ve nitel olarak geliştirdiğini göstermiştir. Sağlık profesyonellerinin farmakovijilans programına aktif katılımı AíR bildiriminin iyileştirilmesi açısından katkı sağlayabilir. ${ }^{12-16}$

Hemşirelerin farmakovijilans aktivitelerine dâhil edilmesi, farmakoloji bilgisi ile hemşirelik uygulamalarını bütünleştirme fırsatı sunar. ${ }^{12}$ Ülkemizde yapılan birkaç çalışma hemşirelerin farmakovijilans hakkındaki bilgisinin düşük olduğunu göstermiş olsa da, bu çalışmaların bulgularını genelleştirmek ve AíR'larının yetersiz rapor edilmesinin nedenini değerlendirmek için benzer çalışmalar yapmak gerekmektedir. ${ }^{5,6,11} \mathrm{Bu}$ nedenle bu çalışma Mersin Üniversitesi Hastanesinde görev yapan hemşirelerin farmakovijilans hakkında bilgi, tutum ve davranışlarını değerlendirmek amacıyla yapılmıştır.

\section{Yöntem}

Kesitsel ve tanımlayıı tipte yapılan bu çalışma 15 Ocak 2019-31 Mart 2019 tarihleri arasında Mersin Üniversitesi Hastanesinde gerçekleştirildi. Bu çalışma için hastane başhekimliği ve Mersin Üniversitesi Klinik Araştırmalar Etik Kurulundan onay alındı. Örneklem seçimine gidilmeden, evrenin tamamına (505 hemşire) ulaşılması hedeflendi. Bu çalışmada ankete katılmayı kabul eden ve belirtilen tarihlerde hastanede aktif olarak çalışan hemşirelerin tümünün (410 hemşire) verdiği cevaplar değerlendirildi.

Çalışma anketi, hemşirelerin demografik özelliklerini, farmakovijilansa yönelik bilgilerini, tutumlarını ve uygulamalarını değerlendirmek üzere tasarlanmıştır. Çalışma anketinde demografik özellik ile ilgili 5, bilgi düzeyleri ile ilgili 9, tutumla ilgili 5 ve uygulama ile ilgili 6 soru olmak üzere toplam 25 soru vardı. Anketin ön 
testi, üniversite hastanesinde rastgele seçilen 20 hemşireye uygulandı. Tanımlayıcı istatistikler sayı ve yüzde ile gösterildi. İstatistiksel karşılaştırmalar için "ki kare testi” kullanıldı. P değerinin 0.05 'den küçük olması istatistiksel olarak anlamlı kabul edildi.

\section{Bulgular}

\section{Hemşirelerin Sosyodemografik Özellikleri}

Mersin Üniversitesi Hastanesinde çalışan hemşirelerin sosyodemografik özellikleri Tablo 1'de gösterilmiştir. Çalışmaya katılan hemşirelerin \%75.4'ü kadın, \%24.6'sı erkek, \%48.3'ü 26-35 yaş arasında, \%73.9'u lisans mezunu, \%9.3'ü lisansüstü mezun ve \%35.4'ünün mesleki tecrübesi 1-4 yıl arasındadır. Çalışmaya katılan hemşirelerin \%33.7'si yetişkin servisleri, \%28.3'ü yoğun bakım, \%9'u acil servis, \%6.6'sı poliklinik, \%7.8'si pediatrik servisler ve \%14.6'sı diğer (ameliyathane, anjio vb.) kliniklerde çalışmaktadır.

Tablo 1. Çalışmaya Katılan Hemşirelerin Sosyodemografik Özellikleri ve Dağılımları $(n=410)$

\begin{tabular}{|c|c|c|}
\hline & Kişi Sayısı (n) & Sıklık (\%) \\
\hline \multicolumn{3}{|l|}{ Yaş } \\
\hline $18-25$ & 101 & 24,6 \\
\hline $26-35$ & 198 & 48,3 \\
\hline $36-45$ & 100 & 24,4 \\
\hline 45 yaş ve üzeri & 11 & 2,7 \\
\hline \multicolumn{3}{|l|}{ Cinsiyet } \\
\hline Kadın & 309 & 75,4 \\
\hline Erkek & 101 & 24,6 \\
\hline \multicolumn{3}{|l|}{ Eğitim Durumu } \\
\hline Lise & 30 & 7,3 \\
\hline Ön lisans & 39 & 9,5 \\
\hline Lisans & 303 & 73,9 \\
\hline Yüksek lisans/Doktora & 38 & 9,3 \\
\hline \multicolumn{3}{|l|}{ Mesleki Tecrübe } \\
\hline 1-4 yıl & 145 & 35,4 \\
\hline $5-9$ yıl & 105 & 25,6 \\
\hline $10-14$ yıl & 79 & 19,3 \\
\hline 15 yıl ve üzeri & 81 & 19,8 \\
\hline \multicolumn{3}{|l|}{ Çalıştığı Birim } \\
\hline Yetişkin servisleri & 138 & 33,7 \\
\hline Yoğun bakım & 116 & 28,3 \\
\hline Acil servis & 37 & 9 \\
\hline Poliklinik & 27 & 6,6 \\
\hline Pediatri servisleri & 32 & 7,8 \\
\hline Diğer & 60 & 14,6 \\
\hline
\end{tabular}

\section{Hemşirelerin Farmakovijilans ile İlgili Bilgi Düzeyleri}

Hemşirelerin farmakovijilans ile ilgili bilgi düzeylerini ölçmeye yönelik sorulara verdikleri yanıtlar Tablo 2'de özetlenmiştir. Çalışmaya katılan hemşirelerin \%83,9'u farmakovijilansın tanımına doğru cevap vermiştir. Hemşirelerin \%52'si farmakovijilansın en önemli amacının ilaç güvenliğini belirlemek olduğunu bildirmiştir. Öte yandan, hemşirelerin \%45.4'ü Türkiye'de bir Farmakovijilans Merkezi'nin (TÜFAM) olduğunu belirtmiştir. Türkiye'de AíR'larının izlenmesinden sorumlu kurumunun TÜFAM olduğunu bildiren hemşireler ise çalışmaya katılanların \%36.8'ini oluşturmaktadır. Hastanede bir farmakovijilans irtibat noktasının olduğunun hemşirelerin \%40.7'si farkındadır. Hemşirelerin \%92.9'u AiR' larının bildiriminin gerekli olduğunu söylemektedir. Çalışmaya katılan hemşirelerin \%84.4'ü hastanede AiR'larını bildirmekten sorumlu sağlık çalışanlarından birinin de hemşire olduğunu ifade etmiştir. Ciddi AiR'larının ne olduğu sorulduğunda verilen cevaplar incelendiğinde; hemşirelerin \%91.2'si ölüm ve/veya hayati tehlike, \%65.4'ü hastaneye yatış/hastanede yatış süresinin uzaması, \%76.3'ü önemli veya kalıcı sakatlığa veya iş görmezliğe neden olmak ve \%48.5'i konjenital anomali ve/veya doğumsal defekt olarak cevaplamışlardır. Yaşanan bir AiR'nunu 15 gün içerisinde bildirmesi gerektiğini bilen hemşireler ise çalışmaya katılanların \%7.1'idir. 
Tablo 2. Hemşirelerin Farmakovijilans ile İlgili Bilgi Düzeylerini Ölçmeye Yönelik Sorulara Verdikleri Yanıtlar ( $n=410)$

\begin{tabular}{|c|c|c|}
\hline & Kişi Sayısı (n) & Sıklık (\%) \\
\hline \multicolumn{3}{|l|}{ Farmakovijilansın en iyi tanımı hangisidir? } \\
\hline İlaç pazarlandıktan sonra AîR'larının türünü ve görülme sıklı̆ını tespit eden bilim & 26 & 6,3 \\
\hline Bir hastane de meydana gelen AíR' larını izleyen bilim & 21 & 5,1 \\
\hline İlacın güvenliğini iyileştirme süreci & 19 & 4,6 \\
\hline $\begin{array}{l}\text { AíR'larının tespiti, değerlendirilmesi, anlaşılması ve önlenmesi ile ilgili etkinlikleri } \\
\text { izleyen bilim }\end{array}$ & 344 & 83,9 \\
\hline \multicolumn{3}{|l|}{ Farmakovijilansın en önemli amacı nedir? } \\
\hline Illaç güvenliğini belirlemek & 213 & 52 \\
\hline AiR'larının insidansını hesaplamak & 71 & 17,3 \\
\hline AiR'ları için kolaylaştırıcı faktörleri belirlemek & 31 & 7,6 \\
\hline Önceden tanınmayan AíR'larını tanımlamak & 95 & 23,2 \\
\hline \multicolumn{3}{|l|}{ Türkiye'de Farmakovijilans Merkezi var mı? } \\
\hline Evet & 186 & 45,4 \\
\hline Hayır & 11 & 2,7 \\
\hline Olabilir & 98 & 23,9 \\
\hline Bilmiyorum & 115 & 28 \\
\hline \multicolumn{3}{|l|}{ Türkiye'de AíR'larının izlenmesinden hangi kurum sorumludur? } \\
\hline Türkiye Farmakovijilans Derneği & 107 & 26,1 \\
\hline Türkiye Illaç ve Tıbbi Cihaz Kurumu & 90 & 22 \\
\hline TÜFAM & 151 & 36,8 \\
\hline Türk Tabipleri Birliği & 28 & 6,8 \\
\hline Böyle bir kurum bulunmamaktadır & 34 & 8,3 \\
\hline \multicolumn{3}{|l|}{ Hastanenizde farmakovijilans irtibat noktası var mı? } \\
\hline Evet & 167 & 40,7 \\
\hline Hayır & 61 & 14,9 \\
\hline Henüz kurulmamış & 8 & 2 \\
\hline Bilmiyorum & 174 & 42,4 \\
\hline \multicolumn{3}{|l|}{ AiR'larının bildiriminin gerekli olduğunu düşünüyor musunuz? } \\
\hline Evet & 381 & 92,9 \\
\hline Hayır & 5 & 1,2 \\
\hline Olabilir & 20 & 4,9 \\
\hline Bilmiyorum & 4 & 1 \\
\hline \multicolumn{3}{|l|}{ Bir hastanede AiR'larını bildirmekten sorumlu sağlık çalışanları kimlerdir?* } \\
\hline Doktor & 340 & 82,9 \\
\hline Hemşire & 346 & 84,4 \\
\hline Eczacl & 275 & 67,1 \\
\hline Diş hekimi & 144 & 35,1 \\
\hline \multicolumn{3}{|l|}{ Aşağıdakilerden hangisi/hangileri ciddi bir AíR'dur ?* } \\
\hline Ölüm ve/veya hayati tehlike, & 374 & 91,2 \\
\hline Hastaneye yatış / hastanede yatış süresinin uzaması, & 268 & 65,4 \\
\hline Önemli veya kalıcı sakatlığa veya iş görmezliğe neden olmak, & 313 & 76,3 \\
\hline Konjenital anomali ve/veya doğumsal defekt, & 199 & 48,5 \\
\hline \multicolumn{3}{|l|}{ Yaşanan bir AiR'nu kaç gün içerisinde ilgili kuruma bildirmelisiniz? } \\
\hline 1 gün & 261 & 63,7 \\
\hline 7 gün & 108 & 26,3 \\
\hline 15 gün & 29 & 7,1 \\
\hline 28 gün & 12 & 2,9 \\
\hline
\end{tabular}

* Birden fazla seçenek işaretlenebilen sorular.

\section{Hemşirelerin Farmakovijilans ile ilgili Tutumları}

Mersin Üniversitesi Hastanesinde çalışan hemşirelerin farmakovijilans ile ilgili tutumlarını gösteren bulgular Tablo 3'de ifade edilmiştir. Hemşirelerin \%81.7'si AíR'larının bildiriminin profesyonel bir yükümlülük olduğunun farkındadır. AíR'larından şüphelenildiğinde hemşirelerin \%83.2'si ilacın kesilmesi ve/veya alternatif ilaç ile tedavi edilmesi gerektiğini, \%77.6'sı da AiR'larının bildirmesi gerektiğini ifade etmiştir. Hemşirelerin \%87.6'sı farmakovijilansın sağlık çalışanlarına ayrıntılı olarak öğretilmesi gerektiğini bildirmektedir. Hemşirelerin \%81.7'si her hastanede farmakovijilans irtibat noktasının olması gerektiğinin farkındadır. "Aşağıdaki faktörlerden hangileri sizi yaşanan bir AíR'nunu bildirmekten vazgeçirir?" sorusuna çalışmaya katılan hemşirelerden \%75.1'i AiR'nun meydana gelip gelmediğine karar vermenin zor olması ( $P$ 
$<0,001), \% 36.6$ 'sı AíR'nunu bildirmek için yeterli zamanın olmadığı $(P<0,001)$ cevabını vermişlerdir. Bununla birlikte hemşirelerin \%21.2'si bildirim yapmanın ücret karşılığının olmamasını ve \%20.2'si ise bildirilmeyen sadece bir vakanın AíR veri tabanını zaten etkilemeyebileceğini düşündüklerini bildirim yapmamalarına sebep olarak göstermişlerdir.

Tablo 3. Hemşirelerin Farmakovijilans ile İlgili Tutum Sorularına Verdiği Yanıtlar ( $n=410)$

\begin{tabular}{|c|c|c|}
\hline & Kişi Sayısı (n) & Sıklık (\%) \\
\hline \multicolumn{3}{|l|}{$\begin{array}{l}\text { AiR'larının bildiriminin sizin için profesyonel bir yükümlülük olduğunu } \\
\text { düşünüyor musunuz? }\end{array}$} \\
\hline Evet & 335 & 81,7 \\
\hline Hayır & 17 & 4,1 \\
\hline Olabilir & 48 & 11,7 \\
\hline Bilmiyorum & 10 & 2,4 \\
\hline \multicolumn{3}{|l|}{ AiR'larından şüphelenildiğinde ne yapılmalıdır?* } \\
\hline İlaç kesilmeli ve/veya alternatif ilaç ile tedavi edilmeli & 341 & 83,2 \\
\hline İlaç kesilmeli ve/veya doz azaltılmalı & 122 & 29,8 \\
\hline Nedensellik belirlenmeli & 178 & 43,4 \\
\hline AíR’ları bildirilmeli & 318 & 77,6 \\
\hline \multicolumn{3}{|l|}{$\begin{array}{l}\text { Farmakovijilansın sağlık çalışanlarına ayrıntılı olarak öğretilmesi } \\
\text { gerektiğini düşünüyor musunuz? }\end{array}$} \\
\hline Evet & 359 & 87,6 \\
\hline Hayır & 12 & 2,9 \\
\hline Olabilir & 36 & 8,8 \\
\hline Bilmiyorum & 3 & 0,7 \\
\hline \multicolumn{3}{|l|}{$\begin{array}{l}\text { Her hastanede farmakovijilans irtibat noktası kurulmasına ilişkin fikriniz } \\
\text { nedir? }\end{array}$} \\
\hline Her hastanede olmalı & 335 & 81,7 \\
\hline Bir şehirde bir tane yeterli & 31 & 7,6 \\
\hline Her hastanede gerekli değil & 9 & 2,2 \\
\hline Hastanelerde ki yatak sayısına göre değişir & 35 & 8,5 \\
\hline \multicolumn{3}{|l|}{$\begin{array}{l}\text { Aşağıdaki faktörlerden hangileri sizi yaşanan bir AíR'nunu bildirmekten } \\
\text { vazgeçirir?* }\end{array}$} \\
\hline Bidirim yapmanın ücret karşıı̆̆ının olmaması, & 87 & 21,2 \\
\hline AiR’nu bildirmek için yeterli zamanın olmaması, & 150 & 36,6 \\
\hline Bildirilmeyen tek bir vaka AíR'nu veri tabanını zaten etkilemeyebilir & 83 & 20,2 \\
\hline AiR'larının meydana gelip gelmediğine karar vermenin zor olması & 308 & 75,1 \\
\hline
\end{tabular}

* Birden fazla seçenek işaretlenebilen sorular.

\section{Hemşirelerin Farmakovijilans ile ilgili Uygulamaları}

Mersin Üniversitesi Hastanesinde çalışan hemşirelerin farmakovijilans ile ilgili uygulamalarına yönelik sorulara verdikleri yanıtları Tablo 4' de gösterilmiştir. AiR'larının tanımlanmasında hemşirelerin \%82.4'ü ilaç bilgi formu/prospektüs kullanmakta, \%69.3'ü ise doktor/eczacıya danışmaktadır. Hemşirelerin \%48.8'i daha önce bir AiR'nu gördüğünü bildirmekle birlikte sadece \%0.2'si (n=1) AíR bildirimi yapmıştır. \%56.8'i ise advers etki bildirim formunu daha önce hiç görmediklerini ifade etmektedir. Hemşirelerin \%54.9'u AiR'nunun nasıl rapor edeceği konusunda hiç eğitim almadı̆̆ını belirtmiştir $(P<0,001)$. Farmakovijilans irtibat noktası tarafından AíR'larının bildirilmesi süreci hakkında bilgilendirilen hemşire oranının ise \%26.1 olduğu tespit edilmiştir. 
Tablo 4. Hemşirelerin Farmakovijilans Uygulamaları ile ilgili Sorulara Verdiği Yanıtlar ( $n=410)$

\begin{tabular}{|c|c|c|}
\hline & Kişi Sayısı (n) & Sıklık (\%) \\
\hline \multicolumn{3}{|c|}{ AíR'larını tanımlamak için hangi yöntemleri kullanıyorsunuz?* } \\
\hline İnternet kaynakları & 218 & 53,2 \\
\hline İlaç bilgi formu/prospektüs & 338 & 82,4 \\
\hline Doktor/Eczacıya danışmak & 284 & 69,3 \\
\hline Üretici firmaya danışmak & 61 & 14,9 \\
\hline Hiçbiri & 11 & 2,7 \\
\hline \multicolumn{3}{|c|}{ Bugüne kadar hiç AíR’u gördünüz mü? } \\
\hline Evet & 200 & 48,8 \\
\hline Hayır & 171 & 41,7 \\
\hline Olabilir & 29 & 7,1 \\
\hline Bilmiyorum & 10 & 2,4 \\
\hline \multicolumn{3}{|c|}{ Advers Etki Bildirim Formunu hiç gördünüz mü? } \\
\hline Evet & 159 & 38,8 \\
\hline Hayır & 233 & 56,8 \\
\hline Olabilir & 11 & 2,7 \\
\hline Bilmiyorum & 7 & 1,7 \\
\hline \multicolumn{3}{|c|}{ Bugüne kadar kaç tane “Advers Etki Bildirim Formu” doldurdunuz? } \\
\hline Hiç & 409 & 99,8 \\
\hline $1-2$ & 1 & 0,2 \\
\hline \multicolumn{3}{|c|}{ AíR'nunu nasıl rapor edeceğiniz konusunda hiç eğitim aldınız mı? } \\
\hline Evet & 127 & 31 \\
\hline Hayır & 225 & 54,9 \\
\hline Hatırlamıyorum & 58 & 14,1 \\
\hline \multicolumn{3}{|c|}{$\begin{array}{l}\text { Kurumunuz veya Hastaneniz Farmakovijilans irtibat noktası } \\
\text { tarafından AiR'larının bildirilmesi süreci hakkında bilgilendiriliyor } \\
\text { musunuz? }\end{array}$} \\
\hline Evet & 107 & 26,1 \\
\hline Hayır & 161 & 39,3 \\
\hline Sadece eğitim & 51 & 12,4 \\
\hline Bilmiyorum & 91 & 22,2 \\
\hline
\end{tabular}

* Birden fazla seçenek işaretlenebilen sorular.

\section{Tartışma}

Bu çalışmada Mersin Üniversitesi Hastanesinde görev yapan hemşirelerin farmakovijilansa yönelik bilgi, tutum ve uygulamaları araştırıldı. Ankete katılan hemşirelerin AiR'larını raporlamalarının profesyonel bir yükümlülük olduğu konusunda hem fikir olması (\%81.7) ve farmakovijilansın sağlık çalışanlarına ayrıntılı olarak öğretilmesi gerektiğini düşünmeleri (\%87.6) çalışmanın önemli bulgularındandır. Bu çalışmada, çalışmaya katılan hemşirelerin çoğunluğunun (\%48.8) daha önce gelişen bir AíR'nunu gördüğünü söylemesine rağmen neredeyse yok denecek kadar az AiR bildirimi yapılmış olması $(\% 0.2, n=1)$ bu anket çalışmasının en çarpıcı sonuçlarından biridir. Ülkemizde yapılan diğer çalışmalarda da hemşirelerin AíR bildirim oranlarının düşük olduğu gösterilmiştir. ${ }^{5,11,17}$ Öte yandan çalışmamız yetersiz/eksik AíR raporlamaya neden olan faktörler (ücret karşılığının olmaması, AíR'nunu bildirecek yeterli zaman olmaması, bildirilmeyen sadece bir vakanın AiR veri tabanını etkilemeyebileceği inancı, AíR'nun gelişip gelişmediğine karar vermede yaşanan zorluk ve eğitim eksikliği) hakkında da fikir vermektedir. Çalışmaya katılan hemşirelerin bir kısmının (\%31) AíR'nunu nasıl rapor edeceği konusunda eğitim aldığını ve bu sayının yeterli olmadığını görmekteyiz. Bununla birlikte farmakovijilans irtibat noktası tarafından AiR'larının bildirilme süreci hakkında bilgilendirildiğini ifade edenlerin oranı ise (\%26.1) neden yeterince bildirim yapılmadığı konusunda fikir verebilmektedir. Çalışmaya katılan hemşirelerin büyük çoğunluğunun lisans mezunu (\%73.9) olduğunu göz önünde bulundurduğumuzda ise hemşirelik lisans eğitim müfredatında farmakovijilans eğitimine daha fazla önem verilmesi gerektiği önerilebilir. Benzer şekilde yapılan diğer çalışmalar da hemşirelerin ulusal ve küresel olarak farmakovijilans sistemindeki kilit rollerini tanımalarını ve farmakovijilans hakkındaki farkındalıklarını artırmaları için hemşirelik lisans ve lisansüstü eğitimine bu konunun dâhil edilmesinin gerekliliğini vurgulamaktadır. ${ }^{19}$

Hemşirelerin farmakovijilansın tanımınını ve en önemli amacını yüksek oranlarda doğru cevaplamaları, AíR'larının bildiriminin gerekli olduğunun (\%92.9) farkında olmaları ve ciddi AíR'larını doğru olarak 
tanımlamaları bize hemşirelerin farmakovijilans hakkında bir bilgisinin olduğunu işaret etmektedir. Buna rağmen hemşirelerin Türkiye'de AiR'larının izlenmesinden sorumlu kurumunun TÜFAM olduğunu (\%36.8) ve gerçekleşen bir AíR'nunu 15 gün içerisinde bildirme gerekliliğini (\%7.1) yeterince bilmedikleri dikkat çekmektedir. Bununla birlikte, çalışmaya katılan hemşirelerin farmakovijilansın sağlık çalışanlarına ayrıntılı öğretilmesi gerektiğinin farkında olması bize sorunun çözümünde paydaş olabileceklerini işaret etmektedir.

Öte yandan AíR'larının bildiriminin profesyonel bir yükümlülük olduğunun bilincinde olmaları ile birlikte hemşirelerin AíR'larından şüphelenildiğinde ilacın kesilmesi ve/veya alternatif ilaç ile tedavi edilmesi gerektiğini (\%83.2) ve AíR'larını bildirmenin önemini bilmesi de (\%77.6) ayrıca önem arz etmektedir. Çalışmaya katılan hemşirelerden farmakovijilansın tanımına doğru yanıt verenleri AíR'nunu bildirmekten vazgeçiren faktörler nelerdir diye incelendiğinde aslında hemşirelerin AiR'nunun gelişip gelişmediğine karar vermede zorluk yaşadıklarını görmekteyiz ve buna ilaveten mevcut iş yüklerinin fazla olmasından dolayı yeterli zaman bulamamalarının da bildirim yapmaları açııından en önemli engellerden biri olarak karşımıza çıktığını görmekteyiz. Bizim çalışmamızın sonuçları ile benzer şekilde Toklu ve arkadaşlarının yaptığı bir başka çalışmada da sağlık profesyonelleri arasında AíR'nun düşük rapor edilmesinin nedenleri arasında AiR bildirim formları hakkında bilgi eksikliği ve bildirim için yeterli zamanın olmaması gibi gerekçeler karşımıza çıkmaktadır. Aynı zamanda hemşirelerin çoğunluğunun (\%59) AiR'na karar vermek için yeterli klinik bilgiye sahip olmadığı da bu çalışmada bildirmiştir. ${ }^{18}$

Opri S ve arkadaşlarının yaptığı bir çalışmada ise 6 ay süre ile iki devlet hastanesinde 174 hemşire 4608 hastayı izlemiş ve bu hastaların \% 53.3'ünde bir veya daha fazla beklenmeyen advers olay saptanmış ancak sadece \% 3.5'i AiR'nu olarak tanımlanmıştır. ${ }^{16}$ Söz konusu bu çalışmada da çalışmamız ile benzer sonuçlara bildirilmiş olup hemşirelerin advers olayları tanımlama oranlarının yeterince yüksek olmadığı görülmektedir.

Çalışmamız tek merkezde yapılmış olduğundan konu hakkında genelleme yapmayı kısıtlıyor gibi görünse de benzer çalışmalar ile desteklenen bulgularımıza göre AiR raporlamada eksiklikler mevcut olup söz konusu eksiklerin nedeni daha net olarak ortaya konmalı ve bu nedenler doğrultusunda AíR raporlama oranının artırılması için gerekli düzenlemeler yapılmalıdır.

Çalışmaya katılan hemşirelerin nerede ise yarısı (\%48.8) yaşanan bir AiR'na şahit olduklarını ifade etmekteler. Hemşirelerin büyük çoğunluğu (\%82.4) AíR'larının tanımlanmasında ilaç bilgi formu/prospektüs kullandığını yada doktor/eczacıya danışığını (\%69.3') bildirmektedir. Bu çalışmada AíR raporlamasının çok düşük olmasının nedenleri arasında hemşirelerin çoğunluğunun çalıştığı kurumda farmakovijilans irtibat noktasının var olduğunu bilmiyor olması, advers etki bildirim formunu kliniklerde hiç görmemeleri (\%56.8) ve çok az bir kısmının AiR'nu nasıl rapor edeceği konusunda eğitim almış olması sayılabilir. Bu sonuçlar bize hemşirelerin farmakovijilans uygulamalarına yönelik eksiklikleri olduğunu göstermektedir. AíR'nu bildiriminin gerekli olduğunu bildiren/düşünen hemşirelerin önemli bir kısmının AíR'larını rapor etmek ile ilgili eğitim eksikliği olduğu göze çarpmaktadır. Bu nedenle hastanelerde advers ilaç raporlama ile ilgili eğitimlerin daha sık ve düzenli yapılması önerilmektedir. Ergün ve arkadaşlarının yaptığı çalışmada hemşirelerin AiR ile karşılaşma sıklığının hekimlere göre düşük olmasına rağmen raporlama oranının hemşirelerde daha yüksek olduğunu göstermiş olması ${ }^{5}$, hastanemizde hemşirelerde düşük olan AiR bildiriminin de gerekli önlemler sonucu artırabileceğini işaret etmektedir. Yine ülkemizde yapılan bir başka çalışmada da bizim çalışmamızla uyumlu olarak hemşirelerin AiR'larının raporlamasının önemini bilmesine rağmen, raporlama oranının düşük olduğu gösterilmiştir. ${ }^{17}$ Bir devlet hastanesinde yapılan başka bir çalışmada ise, hemşirelerin büyük bir çoğunluğu (\%70) ilaç uygulamaları esnasında advers etki gözlendiğinde, bildirilmesi gerektiğini bilmesine rağmen, bildirimlerin farmakovijilans sorumlusuna ve TÜFAM'a iletilmesi gerektiği konusunda farkındalıkları oldukça düşük bulunmuştur. ${ }^{20}$

Yapılan çalışmalar sağlık profesyonellerinin eğitiminin, AíR'nu eksik raporlama oranlarını olumlu yönde etkileyebileceğine dair kanıtlar sunmakta ve bu konuda daha fazla eğitim ve öğretime ihtiyaç olduğu bildirilmektedir. ${ }^{2}$ Öte yandan hemşirelerin akılcı ilaç kullanımına yönelik tutum ve davranışları ile kişilik özellikleri arasındaki ilişkiyi analiz eden bir başka çalışma da, hemşirelerin advers etki bildirim oranları ile gelişime açıklık boyutu arasında anlamlı bir ilişkinin olduğu göstermiştir. ${ }^{21} \mathrm{Bu}$ nedenle eğitimin kişisel gelişime katkılarının ve pozitif sonuçlarının da göz ardı edilmemesi gerekmektedir. 
Bizim çalışmamızın sonuçları ile benzer yönde ülkemizde farmakovijilansla ile ilgili yapılan birçok çalışmada sağlık profesyonellerinin (doktor, ebe/hemşireve eczacıların) farmakovijilans konusunda yeterli bilgiye sahip olmadığı anlaşılmaktadır. ${ }^{5,7,9,11,17,18}$ Türkiye'deki farklı hastanelerin sağı̆ık profesyonellerinin farmakovijilansa yönelik bilgi, tutum ve uygulamalarında tespit edilen farklılıkların TÜFAM kontrolünde yapılan standardize edilmiş bir program çerçevesinde farmakovijilans irtibat noktaları aracıllı̆ında verilen düzenli ve kontrol edilen eğitimlerle düzeltilebileceği öngörülmektedir. Ayrıca farmakovijilansın tüm yönleriyle dinamik gelişimine ve devamına ihtiyaç olduğu ve ilaç güvenliği için başta kurumlara ve sağlık profesyonellerine sorumluluklar düştüğü de bilinmektedir. ${ }^{22}$

Ülkemizde 2005-2014 yılları arasında TÜFAM'a gönderilen AíR raporlarını; raporlama oranı, hasta özellikleri, AiR tipleri, şüpheli ilaçlar, raporun kaynağı ve gönderenin mesleği açısından analiz eden bir çalışma, yıllık raporlama oranının 9 yıllık çalışma süresi boyunca kademeli olarak arttığını ve bu artışın farmakovijilans aktivitelerine paralel olduğunu göstermiştir. ${ }^{7}$ Yine yapılan bir başka çalışmada hemşire ve ebelerin farmakovijilans uygulamaları konusunda yeterli bilgiye sahip olmadığı gösterilmiş ve bu nedenle, lisans ve lisansüstü eğitim programlarına farmakovijilans eğitiminin dâhil edilmesi gerektiğini önerilmiştir. Ayrıca söz konusu çalışmada advers reaksiyonların rapor edilmesini teşvik etmenin esas olduğu da bildirmiştir. ${ }^{11}$

İnsanoğlunun yaşam süresini ve konforunu arttırmak amacı ile geliştirilen ve kullanılan ilaçların toplum sağlığı açısından hiçbir riski yokmuş gibi rahat ve takipsiz kullanılması nedeni ile önemli sayıda insan ilaç advers etkilerine maruz kalmaktadır. Bu nedenle yürütülen farmakovijilans aktiviteleri toplumun bu konuda öngörüsünü ve bilgisini arttırmak açısından da önem arzetmektedir. ${ }^{22}$ Bu bağlamda da hemşireler dâhil tüm sağlık profesyonellerine önemli görevler düşmektedir.

\section{Sonuç}

Sonuç olarak bu çalışmada üniversitemiz hastanesinde görev yapan hemşirelerin farmakovijilans ile ilgili bilgi, tutum ve uygulamalarında eksiklikleri olduğu tespit edilmiştir. Hastanelerde sağlık profesyonellerinin farmakovijilansa yönelik bilgi, tutum ve uygulamada tespit edilen farklılıkların giderilmesinde TÜFAM ve farmakovijilans irtibat noktaları tarafından düzenli ve sürekli eğitim verilmesi önemlidir. Farmakovijilans uygulamaları ve AíR bildiriminin artırımasının yanısıra farmakovijilans irtibat noktalarının eğitim programlarını yürütmede de önemli role sahip olması gerekmektedir. Ayrıca hemşirelerin lisans ve lisansüstü programlarına farmakovijilans eğitimi dâhil edilmeli ve hastanelerde farmakovijilans eğitimi almış hemşirelerin gerekli eğitim uygulamaları ve süreçte yer alması sağlanmalıdır. Bu durum AíR'larının daha yüksek oranda rapor edilmesine katkı sağlayabilir.

\section{Kaynaklar}

1. World Health Organization (2002) Safety of medicines: A guide to detecting and reporting adverse drug reactions:why health professionals need to take action. Geneva: World Health Organization; 2002.

2. Campbell JE, Gossell-Williams M, Lee MG. A Review of Pharmacovigilance. West Indian Med J 2014;63(7):771.

3. Lindquist M, Edwards IR. The WHO Programme for International Drug Monitoring, its database, and the technical support of the Uppsala Monitoring Center. J Rheumatol 2001;28:1180-7.

4. Ithnin M, et al. Mobile App Design, Development, and Publication for Adverse Drug Reaction Assessments of Causality, Severity, and Preventability. JMIR Mhealth Uhealth 2017;5(5):e78.

5. Ergün $Y$, et al. Knowledge attitude and practice of Turkish health professionals towards pharmacovigilance in a university hospital. Int Health 2019;11(3):177-184.

6. Bhagavathula AS, at al. Health Professionals' Knowledge, Attitudes and Practices about Pharmacovigilance in India: A Systematic Review and Meta-Analysis. PLoS One 2016;11(3):e0152221.

7. Ozcan G, et al. Adverse drug reaction reporting pattern in Turkey: analysis of the national database in the context of the first pharmacovigilance legislation. Drugs Real World Outcomes 2016;3:33-43.

8. Sardaş S. Farmakogenovijilans. Turkiye Klinikleri J Pharmacol-Special Topics 2016;4(3):1-7.

9. Toklu HZ, Uysal MK. The knowledge and attitude of the Turkish community pharmacists toward pharmacovigilance in the Kadikoy district of Istanbul. Pharm World Sci 2008; 30:556-562.

10. Taylan S, Alan S, Kadıoğlu S. Hemşirelik Rolleri ve Özerklik. Hemşirelikte Araştırma Geliştirme Dergisi 2012 -2. 
11. Alan S, et al. An evaluation of knowledge of pharmacovigilance among nurses and midwives in Turkey. Indian J Pharmacol 2013;45:616-18.

12. Conforti A, et al. Adverse drug reaction reporting by nurses: analysis of Italian pharmacovigilance database. Pharmacoepidemiology and drug safety 2012;21:597-602.

13. Ranganathan SS, et al. The involvement of nurses in reporting suspected adverse drug reactions: experience with the meningococcal vaccination scheme. Br J Clin Pharmacol 2003;56:658-63.

14. Ulfvarson J, Mejyr S, Bergman U. Nurses are increasingly involved in pharmacovigilancein Sweden. Pharmacoepidemiol Drug Saf 2007;16:532-7.

15. Hall M, et al. The spontaneous reporting of adverse drug reactions by nurses. Br J Clin Pharmacol 1995;40:173-5

16. Opri S, et al. Venus study: a research and education project on nurses and drug surveillance. Assist Inferm Ric 2011;30:6-15.

17. Vural F, Çiftçi S, Vural B. The knowledge, attitude and behaviours of nurses about pharmacovigilance, adverse drug reaction and adverse event reporting in a state hospital. North Clin İstanb 2014;1:147-52.

18. Toklu $\mathrm{HZ}$, et al. The knowledge and attitude of the healthcare professionals towards pharmacovigilance and adverse drug reaction reporting in northern Cyprus. J Pharmacovigil 2016;4:1-7.

19. Şavlı E, Şavlı E. The Importance of Pharmacovigilance and Ecopharmacovigilance in Nursing Education. Ordu University Journal of Nursing Studies 2019;2(1):70-8.

20. Vural F, Çiftçi S, Vural B. Sık karşılan ilaç uygulama hataları ve ilaç güvenliği. Acıbadem Üniversitesi Sağlık Bilimleri Dergisi 2014;5(4):271-5.

21. Uzuntarla $Y$, Cihangiroğlu N. The analysis of relationship between nurses' rational use of drugs and their personal characteristic. TAF Preventive Medicine Bulletin 2016;15(1):1-8.

22. Kaya D, Sürmelioğlu N, Karataş Y. Past, Present and Future of Pharmacovigilance. Archives Medical Review Journal 2016;25(1):129-39. 